\title{
O CONCEITO DE POLÍTICA POSTO À PROVA PELA MUNDIALIZAÇÃO'
}

\author{
Catherine Colliot-Thélène \\ Universidade de Rennes/Escola Normal Superior de Fontenay-Saint-Cloud/CNRS
}

\section{RESUMO}

Este artigo procura caracterizar o conceito moderno de política diante dos fenômenos que se designam pelo termo "globalização". Examina-se como o Estado moderno consolidou sua capacidade de dominação à medida em que se revelou capaz de estruturar simbolicamente uma identidade coletiva particular, expressa pela idéia de cidadania. Sustenta-se que a diversificação dos espaços de decisão e a transferência de competências econômicas, jurídicas e militares para instâncias supranacionais, regionais ou transnacionais, ao mesmo tempo em que questiona a soberania estatal, começa a redefinir de modo inédito o espaço da política, visto que as relações de poder, neste novo contexto, deixam de ser acompanhadas por processos de identificação coletiva, até agora assegurados pela capacidade de decisão do Estado.

PALAVRAS-CHAVE: política; Estado; soberania; identificação coletiva; globalização; mundialização.

\section{A NOÇÃO MODERNA DE POLÍTICA}

É evidentemente arriscado comprometer-se com uma determinada definição de política, mesmo que essa definição seja limitada à compreensão moderna do que política quer dizer. Esse conceito é ele mesmo objeto de discussão, discussão na qual se reflete a diversidade de abordagens e tradições que contribuíram para a redação dos textos do corpus da Filosofia Política ou da teoria política moderna. Entre Hegel e Tocqueville, os filósofos contratualistas e Marx, Rousseau e Hannah Arendt, as divergências não dizem respeito tão-somente às respostas que seriam dadas a um conjunto de questões sobre as quais existiria concordância geral. As questões diretrizes variam, e tanto a localização da política (notadamente sua relação com o econômico e o social) quanto suas implicações (a liberdade, a emancipação, o poder?) são interpretadas diferentemente de um autor para outro, a ponto de desencorajar toda tentativa de caracterização unívoca de um conceito de política que seria próprio dos modernos. Nessas condições, é com-

\footnotetext{
1 Este texto, com o título L e conopt de politique à l'epreuve de la mondialisation, foi apresentado no Colóquio "Política na mundialização, mundialização da Política", em Hamburgo, em 1997. Tradução do francês e do alemão: Luciano Nervo Codato. Revisão técnica: Vinicius de Figueiredo.
}

preensível que seja extremamente difícil apreciar as transformações que o fenômeno que se designa pelo termo mundialização pode induzir para o entendimento da política, assim como as conseqüências que devemos extrair daí no plano conceitual.

As variações da apreensão da política não dizem respeito unicamente às posições dos autores que defendem uma ou outra definição, mas também - e talvez sobretudo - à diversidade das tradições nacionais e conjunturas. E o risco é sempre grande de elevar à condição de essência da política uma maneira de vivê-la e compreendêla que corresponde tão-só à experiência de uma geração, em uma ou algumas décadas, em um espaço geográfico limitado. Não se pode compreender seriamente Maquiavel sem levar em conta as lutas internas e externas das cidades-Estado da Itália do século XV, Hobbes sem o pano de fundo das guerras religiosas, Hegel sem as guerras napoleônicas, as lutas de libertação sem a obra dos grandes Reformadores etc. Nada mais banal que essa exigência de contextualização, porém é bom evocá-la antes de aventurar-se, na base de uma experiência ela também circunscrita geografica e temporalmente, em diagnósticos temerários sobre o estado presente e o provável devir do conceito moderno de política. Em suma, qualquer um que fale em mudanças hoje em dia e acredite ler em 
nossa contemporaneidade as premissas de uma compreensão radicalmente nova da política deve se sujeitar à exigência metodológica mínima de precisar a escala de seu diagnóstico. Os acontecimentos que marcam época não são identificáveis de maneira relativamente precisa senão com o distanciamento de várias décadas, talvez de vários séculos. O saque de Roma pelas hordas de Alarico decerto serviu a Agostinho de pretexto para redigir a Cidade de Deus, mas, como se sabe, quando terminou sua obra, havia muito os habitantes do Império Romano já estavam tranqüilos quanto ao destino desse Império que acreditaram definitivamente selado, por um momento, com a queda da capital.

Escala do diagnóstico, portanto. De onde provém o sentimento, bastante compartilhado hoje em dia, de que a política não é mais o que era, de que provavelmente não pode mais sê-lo, ou ainda, em termos certamente datados, de que uma época do espírito foi vivida? Em um primeiro nível, provém da perda dos parâmetros em função dos quais se determinavam os engajamentos e tomadas de posição política durante as três décadas que se seguiram ao fim da II Guerra Mundial: uma certa interpretação da oposição direita/esquerda, por exemplo, que estruturava profundamente o campo da política, conflitante em sua essência (quer dizer, constituído por oposições e lutas), e à qual nos é cada vez mais difícil dar um conteúdo preciso. A essa perda de parâmetro está ligada a aparência derrisória dos jogos políticos tradicionais. Na falta de algo verdadeiramente em jogo nas oposições entre os partidos que disputam entre si as responsabilidades governamentais, a imagem dos políticos em seu conjunto tende a se confundir com aquilo que Max Weber ironicamente denominava Berufspolitiker ohne Beruf [políticos profissionais sem vocação $]^{2}$. Parece-me que esse descompasso entre a cena política, entendida em um sentido estrito, e as preocupações e expectativas dos cidadãos eleitores é um fenômeno recorrente na história dos sistemas parlamentares modernos, e que é preciso alguma prudência antes de inferir a partir daí a obsolência irreversível dessas formas clássicas de expressão política. É ain-

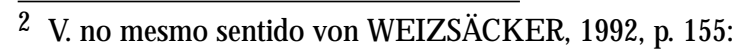
"Entre nós, um político profissional não é, via de regra, nem um especialista, nem um diletante, mas um generalista com um saber específico: o de combater o político adversário". da mais duvidoso invocar esse fenômeno para concluir uma mudança radical do conceito de política que afetaria o papel do próprio Estado. A centralidade do Estado na compreensão moderna do político remonta, com efeito, à formação dos Estados-nação, quer dizer, a um processo histórico esboçado desde o século XVI, confirmado e refletido teoricamente no século XVII, bem antes de os partidos políticos adquirirem o papel institucional que se conhece. Mais importante, em contrapartida, parece-me o sentimento de uma crescente impotência do Estado em assegurar tarefas que não lhe competem senão a partir de um passado recente, mas que durante uma grande parte do século XX (as datas variam segundo os países) têm sido uma das principais fontes de sua legitimidade. Em outros termos, o mal-estar que afeta a política hoje em dia, de onde tiramos a impressão de que é urgente repensá-la, traduz a crise de uma figura historicamente determinada do Estado moderno: aquela do Estado-Providência ou, segundo a fórmula sugerida por Robert Castel com argumentos convincentes, do Estado social ${ }^{3}$. Escala do diagnóstico: o conceito de política que hoje em dia comprovamos problemático é aquele de uma época limitada da história do Estado e, portanto, da política dos modernos. A questão, entretanto, continua aberta: será que nos tornamos simplesmente uma página da história da política moderna, ou antes a crescente incapacidade do Estado de manter a condução de sua política social indica uma transformação mais fundamental, um deslocamento das instâncias de decisão que compromete o futuro dos povos e coloca em xeque não mais uma figura da política moderna, mas o conceito da política dos modernos em geral, na medida em que este se articulava em torno da soberania dos Estados?

Ao formular nesses termos a questão dos efeitos da mundialização sobre o conceito de política, tenho consciência de me antecipar a algumas objeções maiores.

\footnotetext{
3 A capacidade do Estado cumprir as tarefas de uma política social se tornou o teste de sua capacidade de decidir em geral. Cf. CASTEL, 1995, p. 457: "A aposta do debate é ocultada [...] quando se pretende que uma política social diferente é incompatível com a busca de uma política econômica realista e responsável. É tomar por decidido que a aceitação das leis do mercado não deixa nenhuma margem de manobra, o que redunda, aliás, em negar a própria possibilidade da ação política".
} 
Objeções factuais, antes de tudo: será discutido o fato de que a mundialização (quer dizer, os fenômenos que reunimos sob esse termo e cuja análise é também discutida) permite anunciar o fim da soberania dos Estados. Não pretendo entrar aqui em um debate que implica um elenco minucioso das competências econômicas, jurídicas, militares etc. que os grandes Estados europeus conservam ou porventura transferem a instâncias diversas — instâncias não-políticas no interior de seus territórios, tais como bancos centrais independentes - instâncias econômicas supranacionais — Banco Mundial ou FMI —, instâncias políticas ou quase políticas - ONU, instituições européias etc. Seja qual for o resultado que se venha a extrair desse elenco, pode-se tomar por conclusivo, parece-me, que no presente não vivemos um processo de despojamento do Estado em proveito de novos poderes políticos, supranacionais, regionais ou transnacionais, convocados a substituí-lo em um futuro próximo. Nenhuma instância política, seja em um nível regional seja mundial, está apta a reivindicar, a curto ou médio prazos, a totalidade das competências do Estado nacional. Não estou certa, entretanto, se esse gênero de compatibilidade, que visa mostrar que, bem ou mal, o Estado nacional termina por manter algumas prerrogativas, não nos faz passar ao largo do essencial da noção de soberania, a qual não se pode esgotar por uma enumeração das funções do Estado. Bob Jessop, por exemplo, em um artigo intitulado Die Zukunft des Nationalstaats: Erosion oder Reorganisation? [O futuro do Estado nacional: erosão ou reorganização?] (cf. JESSOP, 1997), convida a distinguir entre as funções particulares do Estado, de certo modo contingentes, e suas funções gerais, antes de todas a que consiste em assegurar a integração e coesão sociais. Mas salvo reduzir essa função reconhecida essencial a medidas simplesmente de polícia, é claro que ela se desempenha em grande parte no plano do simbólico, e que essa dimensão simbólica do poder do Estado não é dissociável do conjunto de seus serviços: pode-se duvidar se um Estado que se revelasse abertamente como simples correia de transmissão dos imperativos de um mercado internacional indiferente ao bem-estar das populações pudesse de fato nutrir de forma duradoura o sentimento da identidade cidadã em seus integrantes. E a introdução ou reintrodução da educação cívica na escola não bastará certamente para corrigir uma imagem do Estado forjada no cotidiano vivido das modalidades concretas de sua presença (peso dos serviços obri-gatórios, intervenções repressivas nas periferias) ou de sua ausência (impotência face ao crescimento do desemprego, à insegurança etc.).

Objeções teóricas, de outra parte. Antes de tudo: colocando a soberania do Estado no coração do conceito moderno de política, será que de fato não escolhi uma tradição dos modernos em detrimento de outras, que sublinharão, de preferência, as múltiplas expressões da participação das massas sob as formas institucionalizadas ou selvagens que vão do voto à greve e à manifestação de rua, passando pela discussão das decisões governamentais nos jornais e pelos diferentes foros onde a opinião pública se forma, e mediante os quais exerce uma influência incontestável nas decisões dos políticos e, portanto, nos destinos da coletividade? Será que não sacrifiquei, em suma, a dimensão da cidadania em favor de uma concepção implicitamente decisionista da política, que se valerá de preferência de Hobbes, Hegel, talvez Max Weber ou mesmo Carl Schmitt, em vez do Maquiavel dos Discursos, do Kant teórico da esfera pública, de Marx ou da tradição concilista? Todavia, parece-me que a clivagem que alguns tentam aqui instituir repousa sobre um mal-entendido. Fazer do poder o atributo essencial do político, para nos atermos à definição weberiana ${ }^{4}$, não implica necessariamente negar a realidade e a complexidade do espaço público, nem contestar que todas as formas que assumem a sustentação ou resistência das massas às decisões dos detentores do poder do Estado (aí compreendido inclusive o abandono das seções eleitorais) participam da efetividade da política no sentido dos modernos. E entre outras coisas é esse caráter proteiforme da política, resultado de uma história em que desempenharam um papel decisivo as lutas políticas e sociais da segunda metade do século XIX e da primeira do XX, que torna hoje em dia dificilmente sustentável a distinção que o século XIX estabeleceu entre Estado e sociedade civil. O paradigma no qual Hegel - e depois dele Lorenz von Stein ou Robert Mohl - refletiu sobre a diferença das sociedades modernas em relação à sociedade das ordens e corporações, justificado em sua época, não mais funciona quando se trata de dar conta do funcionamento de Estados cuja ação reguladora

4 Para recordar: "Política, portanto, significaria para nós: aspirar à participação no poder ou à influência na divisão do poder seja entre Estados, seja no interior de um Estado entre os grupos humanos que ele envolve" (WEBER, 1921) 


\section{O CONCEITO DE POLÍTICA POSTO À PROVA PELA MUNDIALIZAÇÃO}

e administrativa se estende aos aspectos mais íntimos da vida privada, instituindo deveres e garantindo direitos em domínios que até há pouco dependiam do livre arbítrio ou da sorte de cada um: por exemplo, o dever de assegurar a subsistência de seus ascendentes ou descendentes, o direito à renda mínima ou à aposentadoria. Que esse paradigma (a diferença e oposição entre sociedade e Estado) esteja há muito obsoleto não impede, entretanto, que o Estado continue a organizar de maneira privilegiada o espaço da política. Dissemos acima que a "crise" que o Estado conhece hoje em dia nas sociedades européias, o déficit de legitimidade que o desinteresse eleitoral eventualmente testemunha e, com mais frequiência, a versatilidade dos eleitores até então, não diz respeito ao Estado moderno em geral (este é uma abstração, e os fundamentos de sua legitimidade, uma questão de teóricos), mas à forma particular com a qual ele progressivamente se revestiu na segunda metade do século XX, cujos traços se delinearam após a II Guerra Mundial e da qual se pode fazer remontar a gênese, ao menos ideológica, até o começo do século. Mas se as funções características do Estado social tornam fluida a distinção entre sociedade e Estado, este permanece uma instância de decisão. É nesta qualidade que o Estado é interpelado por indivíduos, grupos e coletivos, permanentes ou provisórios, que o fazem o destinatário de seus protestos e reivindicações. Aqui pouco importam as clivagens políticas: o liberalismo, entendido politicamente, e as doutrinas "estatistas" em suas diferentes variantes, detêm em comum o fato de atribuir implicitamente ao Estado uma capacidade eminente de intervir nas redes de socialidade para regulá-las, hierarquizá-las, corrigilas etc. A autolimitação reclamada pelos liberais ainda é um ato de vontade. O poder do Estado não se comprova unicamente em suas manifestações violentas (intervenções policiais, guerras) ou nas pesadas coações impostas por sua administração, mas também na faculdade que dispõe de responder às pressões que se exercem sobre ele, uma resposta que toma a forma de escolhas novas legislações, escolha orçamentária etc. Nenhuma teoria do Estado, em verdade, pode se privar de um componente decisionista entendido nesse sentido, e somente a confusão entre a forma da decisão e o arbitrário eventual de suas motivações explica as espantosas resistências para reconhecer esta verdade tão evidente.

\section{SOCIALIDADE ESTATAL versus SOCIA- LIDADE DE REDES}

A análise do Estado moderno oscilou desde sempre entre dois registros. O primeiro é o da ética: sua questão central é a das identidades coletivas, de sua ordem e subordinação. Em outros termos, a Filosofia Política moderna retomou por conta própria a idéia aristotélica de uma organização teleológica das comunidades naturais ("A cidade é o fim de todas as comunidades naturais", Pol. I, 2), substituindo - o que não foi uma modificação anódina — o Estado nacional pela cidade 5 . O segundo registro é aquele da relação entre poderes, em que o Estado não mais se configura como um pólo de identificação, mas um aparelho, um corpo exercendo as funções da administração de bens e homens. Neste sentido ele se acha em relação com outros poderes ${ }^{6}$, quer dizer, em concorrência, o que inclui a possibilidade de conflitos assim como de compromissos e cumplicidades. Esquematicamente, pode-se dizer que a Filosofia privilegiou o primeiro registro: as problemáticas contratualistas podem ser interpretadas nessa perspectiva, e disso decorrem também as indagações clássicas sobre a cidadania ou a democracia, ao passo que as outras disciplinas, notadamente a Sociologia ou a Economia Política (antes de se restringir ao estatuto de uma Economics), assim como os discursos críticos (crítica da economia política ou ainda a crítica da política cujo projeto Marx havia proposto e da qual se pode encontrar os elementos nele e em outros), escolheriam o segundo: nessa ótica a atenção se dirige prioritariamente às formas e meios de dominação que se exercem sobre os integrantes do Estado, que aparecem mais na qualidade de súditos (de dominados, por exemplo, em Max Weber) que de cidadãos. Esquematicamente, dizia; pois é claro que as duas perspectivas não podem ser inteiramente dissociadas. Hegel dispensou um esforço considerável para conciliar ambas as problemáticas, sem que a coisa tenha sido universalmente

\footnotetext{
5 Assim: Hegel, Prinćíios da Filosofia do D ireito, § 258: “A destinação do homem é levar uma vida universal e seu dever supremo é ser membro do Estado".

6 Entendo "poder" [puissanoe] na acepção extensiva, mas não menos operatória, a meu ver, em que Weber utiliza esse termo no título da segunda parte de E conomia e Sociedade: "A economia e as organizações e poderes sociais" (D ieW irtschaft und die gesellschaftlichen Ordnungen und Mächte).
} 
compreendida por seus leitores: aqueles que tomam sua Filosofia do Direito por uma apologia do Estado e o inscrevem na linhagem dos teóricos do Machtstaat [poder do Estado] e da Realpolitik (como Meinecke) negligenciam aquilo que nessa obra depende da questão ética das identidades e sua hierarquia. Mas mesmo em um autor tão resolutamente prosaico como Max Weber, em que as dimensões do poder e da dominação adquirem papel de destaque, pode-se considerar que a temática ética se perfila nos bastidores da teoria das diferentes formas de legitimidade: a "crença" que se requer da parte dos súditos para sustentar a estabilidade de uma dominação não é estranha à maneira pela qual eles resolvem os conflitos identitários.

Uma série de discursos contemporâneos sobre a democracia, a política ou a cidadania esquecem ou subestimam a dimensão do poder do Estado, e as exortações à reinvenção da democracia, do político, da cidadania - como quiserem - desconhecem por isso mesmo aquilo que hoje em dia coloca em perigo essas maneiras de viver o coletivo. A menos que perca toda significação institucional precisa, a democracia é um modo de organização e funcionamento do Estado (como antigamente foi um modo de organização e funcionamento da cidade), quer dizer, da relação entre governantes e governados; e a cidadania é, do mesmo modo, um tipo de pertencimento comunitário que tem como suporte o Estado. Mas se pretendemos apreciar os efeitos da mundialização sobre a compreensão do político, é preciso, em contrapartida, tomar em conjunto os dois registros de interpretação do Estado, quer dizer, é preciso apreendê-lo em sua dupla dimensão de pólo de identificação coletiva e de poder. Pois é em sua qualidade de poder que o Estado está apto a dotar o indivíduo de uma identidade particular, a de súdito ou cidadão, que vem se acrescentar a outras, modificando-lhes o equilíbrio. Idealmente, o Estado aspira à preeminência: ele é a realidade da Idéia ética - como diz Hegel —, e os direitos e deveres vinculados a outras formas de socialidade, família ou diferentes círculos da sociedade civil, são subordinados a ele. Essa subordinação apresentada como uma norma pela filosofia do Estado é o resultado de um processo histórico bastante real, aquele da transferência ao Estado territorial de certas funções e prerrogativas antes assumidas pelas comunidades não-estatais. "O que hoje consideramos as funções fundamentais do Estado" — observa Weber — "a saber: a institui- ção do direito (legislativo), a proteção da segurança pessoal e da ordem pública (polícia), a proteção dos direitos adquiridos (justiça), o encargo da saúde, dos interesses educacionais, políticas sociais e outros interesses culturais (as diferentes áreas da administração), enfim - e notadamente - a proteção violenta organizada e voltada ao exterior (administração militar), não existem nos primeiros momentos ou não existem sob a forma de organizações racionais, mas simplesmente como comunidade ocasional amorfa ou mesmo se acham distribuídas entre comunidades muito diversas: comunidade doméstica, linhagem, grupos vizinhos, comunidade de mercado ou ainda grupos intencionalmente constituídos por objetivos precisos" (WEBER, 1922, p. 516). Se a norma enunciada por Hegel não é um postulado vão, é porque traduz em termos éticos, quer dizer, simbólicos, a preeminência factual do Estado sobre outras formas de fidelidade coletiva: uma relação de forças, portanto - a hegemonia historicamente conquistada de um poder produtor de vínculo social sobre todos os outros, antigos e recentes. É claro que essa hegemonia foi por muito tempo um objetivo visado pelo Estado em relação ao território que reivindicava como seu, mais que uma realidade para o conjunto de seus habitantes. As solidariedades próximas - de vizinhança, de parentesco —, ou tradicionais, notadamente religiosas - com freqüência permaneceram mais concretas e mais fortes que o pertencimento ao Estado, coletivo abstrato e longínquo, para uma grande parte das populações. Perderíamo-nos fazendo aqui o elenco dos múltiplos fatores que contribuíram para a homogeneização progressiva, jamais completamente concluída, das culturas identitárias: redução das distâncias em virtude dos progressos dos transportes, expansão da civilização urbana, difusão da imprensa, serviço nacional e educação pública (especialmente na França), extensão do direito ao voto etc. Resta que a capacidade do Estado de estruturar uma identidade coletiva e subordinar, nessa propensão, todas as outras identidades coletivas, progrediu em compasso com a afirmação de seu poder. Um poder que o cidadão não comprovava apenas como poder coercitivo, mas também como um poder protetor, tanto mais na medida em que se ampliavam os direitos ligados à cidadania (além da justiça e da segurança, igualmente a educação, a saúde, eventualmente a renda mínima, a aposentadoria assegurada).

Ora, chegamos ao ponto que me parece es- 
sencial e que pode deixar supor que, apesar do caráter histórico particular da forma de Estado abalada pelo fenômeno da mundialização, talvez não seja falso pensar que a compreensão moderna da política é por isso mesmo posta em questão. Foi em virtude de sua função simbólica de pólo de identificação que o Estado pôde estruturar o campo da política. Ou melhor: que deu existência a esse campo. A definição weberiana de política pode parecer altamente orientada para a esfera estreita e exclusiva do político, quer dizer, para a atividade dos homens que fazem da política sua profissão, mas permanece pertinente, parece-me, no sentido de que a política se torna uma forma específica da atividade social na medida em que se reporta ao poder de Estado. Ela não visa necessariamente dele se apoderar, no todo ou em parte, mas o pressupõe, quer dizer, pressupõe existir uma instância de poder identificável que decide em última instância os conflitos externos e internos. Em termos mais concisos: à existência do Estado está vinculada a existência de um espaço de socialização original (como era o caso na polis antiga, se seguimos Aristóteles), em relação ao qual todas as outras formas de fidelidade ou dependência coletivas (familiares, étnicas, culturais, econômicas, religiosas) são subordinadas ou mesmo instrumentalizadas.

A capacidade do Estado de assegurar a perpetuação desse espaço, de sustentar portanto uma forma de identidade coletiva particular, é indissociável da efetividade material de seu poder. Dirse-á e repetirá: é certo que o Estado nacional perdeu, ou está em vias de perder, certos atributos da autoridade soberana, porém não está comprometido, em virtude desse fato, em um processo que permita anunciar sua desaparição a curto ou médio prazos. Ele é desde sempre e continuará a ser, nas próximas décadas, um dos poderes cujas decisões contribuem para modelar a evolução das redes de interdependência que hoje em dia constituem o mundo. Um dos poderes, ao lado de outros, parceiros ou concorrentes, ou ambos ao mesmo tempo: instâncias de decisão regionais ou locais, consórcios econômicos transnacionais, instituições supranacionais políticas ou econômicas de maior ou menor envergadura, organizações não-governamentais etc. É nesse “ao lado”, porém, que reside o problema. Ele implica, com efeito, para o súdito/cidadão do Estado, que este não mais possui o caráter de poder supremo. "É pois bastante claro aos meus olhos" - escrevia Hobbes no limiar da época moderna — “[...] que o poder soberano, quer resida em um único homem, como em uma monarquia, quer em uma assembléia, como nas Repúblicas populares ou monárquicas, é tal que não se pode imaginar os homens edificando um maior" (Leviatã, capítulo 20). O desenvolvimento de lógicas de socialização provenientes da interação de múltiplos centros de decisão, entre os quais nenhum está apto a afirmar sua preeminência sobre os outros, produz um novo “poder" que a imaginação dos homens dos século XVII não podia antecipar. Um poder, é verdade, cuja natureza é muito diferente daquilo que Hobbes denominava poder: um poder que, diferentemente do Estado, não é portador de nenhuma identidade coletiva.

A propósito dessa diferença de natureza, algumas especificações são necessárias. O Estado possui de peculiar, em relação a qualquer outra instância de identificação, o fato de ser a encarnação institucional de uma abstração, precisamente aquela que denominamos sua soberania. É essa abstração que Weber notadamente tinha em mente quando falava da impessoalidade da dominação legal, por meio da qual esta se diferencia, segundo ele, tanto da dominação tradicional quanto da carismática, uma e outra vinculadas à autoridade pessoal dos dirigentes. Hegel, por sua vez, falava da idealidade da soberania, expressão que me parece preferível, apesar de seu caráter um pouco desconcertante para um leitor contemporâneo. É certo que a identidade da soberania estatal é independente dos indivíduos concretos que a exercem, e que não está vinculada a uma figura histórica concreta da comunidade (tal como a nação, embora a história da idéia nacional e a da forma estatal sejam estreitamente imbricadas), porém a soberania nem por isso deixa de ser - e este é o ponto que importa para apreciar os efeitos simbólicos da mundialização - uma forma de poder à qual retornam essencialmente os atributos da personalidade 7 . Por esta razão, o Estado é um poder em um sentido muito diferente daquele, por exemplo (exemplo que não é absolutamente mencionado ao acaso, será retomado adiante), em que

\footnotetext{
7 Se ficarmos em Hegel, na Filosofia do D ireito: de um lado a soberania do Estado implica que seus diferentes poderes não podem se tornar autônomos, nem se confundir com a vontade particular dos indivíduos que os exercem. Eis o pensamento abstrato da idealidade (§ 278); de outro lado a soberania só existe "como subjetividade dispondo da certeza de si, como
} 
podem ser ditos "poderes" o mercado ou a economia mundial. Ser soberano envolve a capacidade de decidir, o que é próprio da pessoa: a soberania do Estado se põe à prova e se dá a conhecer e reconhecer como decisão sob a forma do governo ou da elaboração e execução da lei. Diferentemente do termo "impessoalidade", portanto, o termo "idealidade" nos permite de uma só vez sublinhar a abstração do poder do Estado, independentemente das pessoas que o exercem, e o fato de esse poder permanecer, não obstante, da ordem da decisão e do comando. Assim entendida, a idealidade do poder do Estado comporta esta conseqüência importante: se viesse a desaparecer a capacidade do Estado como poder de governar efetivamente, quer dizer, de "dar forma" a um certo coletivo, esse próprio coletivo desmoronaria, pois jamais teve outra substância que essa própria capacidade. Que o Estado seja também nação, certamente lhe permitiu mobilizar em seu proveito, ao longo de toda a sua história, vetores de identificação heterogêneos - comunidade de língua, de história política, de cultura, de religião etc. É certo que a abstração da identidade estatal constituía uma fraqueza em comparação às solidariedades mais próximas, historicamente enraizadas e sobretudo cotidianamente perceptíveis, dos vínculos comunitários tradicionais. Uma fraqueza que manifesta, notadamente na Alemanha, a nostalgia duradoura da Gemeinschaft [comunidade] e a correlativa desconfiança face ao fundamento contratualista da Vergesellschaftung [socialização] estatal. A nação, comunidade imaginária utilizando todos os recursos de que dispõe (língua, cultura, origem étnica etc.), compensaria as carências do Estado no plano das solidariedades vividas. Com efeito, espero não formular um ponto de vista excessivamente francês afirmando que, apesar disso, a identidade estatal é dissociável de sua interpretação nacionalista (o que não impede, bem entendido, que o Estado exista e só possa

autodeterminação abstrata - portanto sem fundamento da vontade, pois é nessa autodeterminação abstrata da vontade que reside o elemento último da decisão" (§ 279). Com este argumento Hegel procura justificar a forma monárquica do regime, o que dará ensejo às observações irônicas de Marx. Todavia, pouco nos importam aqui os prováveis sofismas do argumento. 0 essencial é que o conceito de soberania inclui a idéia de vontade e que o soberano indivíduo ou coletivo - seja pensado com os atributos da pessoa. Este já era o caso em Hobbes, Locke, Spinoza, Rousseau etc. existir sob a forma de Estado-nação) e que, a despeito das guerras e crimes que marcaram a história dos Estados-nacionais no curso dos dois últimos séculos, essa história também pode ser lida como a de uma depuração progressiva do conceito da política, quer dizer, da incorporação — nas disposições, expectativas, representações dos cidadãos de si próprios, ao menos daqueles dos Estados da Europa ocidental — de uma identidade à qual tão-somente a existência do Estado dá substância. A consciência cidadã é o resultado de uma educação histórica para a qual em grande parte contribuiu, notadamente no curso da segunda metade do século XX, a instituição das garantias particulares concedidas pelo Estado social: por meio delas o Estado tornou-se uma espécie de comunidade, no sentido de que estabelecia entre seus integrantes vínculos de solidariedade cuja realidade se comprovava no cotidiano. Em suma, o Estado social nos liberou, até certo ponto, da representação afetiva e imaginária da nação.

A capacidade do Estado de impor sua hegemonia sobre todas as outras formas de fidelidade coletiva diz respeito unicamente à efetividade de sua onipotência. Quando esta falha, os outros modos de identificação, que até há pouco haviam sido instrumentalizados, reencontram uma dinâmica independente (aliás, jamais totalmente perdida) e eventualmente se voltam contra ele. Alguns se regozijam com a relativização do poder do Estado e acreditam desvendar na multiplicação dos centros de poder as condições de uma prática política enfim emancipada do monopólio do Estado. Que um poder dividido entre múltiplas instâncias, escapando a toda hierarquização, permita anunciar um enfraquecimento da compreensão clássica da política, é algo indiscutível. O que é menos claro é o tipo de política que virá depois desse enfraquecimento. O desenvolvimento de lógicas de socialização transcendendo os limites dos Estados despoja o Estado do atributo do poder supremo. Contudo, não se apresenta nenhum novo coletivo capaz de reclamar sua herança, quer dizer, capaz de organizar o campo de uma nova cidadania. Os poderes em relação aos quais a suposta onipotência do Estado se torna estéril não são, com efeito, de uma natureza tal que possam cristalizar processos de identificação. Não é a humanidade européia, ou a humanidade em geral, que se perfila para além do Estado, apesar da retórica pouco convincente com a qual certos organismos internacionais habilitam suas intervenções. As formas mais 


\section{O CONCEITO DE POLÍTICA POSTO À PROVA PELA MUNDIALIZAÇÃO}

eficazes de socialidade transnacional não são as supranacionais: por estas entendo as formas ligadas a entidades jurídico-políticas determináveis, pois constituídas deliberadamente pelos acordos entre Estados. Os dias que sucedem ao Estado soberano não são preparados — como se sabe por um despojamento consentido (ou forçado) dos Estados-nação em proveito de coletividades mais amplas. As aproximações dessas coletividades existiram, ou ainda existem: SDN ontem, ONU hoje. Todavia, apesar de suas pretensões de fachada, elas não foram e nada mais são que um lugar entre outros da luta (policiada) entre as nações. É duvidoso que uma cidadania "onuense" possa algum dia vir à luz. A mundialização traz consigo uma relativização da forma Estado nos processos de identificações coletivas, todavia ela mesma não resulta de uma federação de Estados. Um desmentido do sonho kantiano? Desde o final do século XVIII, entretanto, era claro para os espíritos mais avisados que não seriam os Estados que tratariam de realizar a unificação do mundo. O próprio Kant, embora concebesse as relações de socialidade em uma perspectiva antes de tudo jurídico-política, descartava a idéia de um Estado universal — que só poderia ser despótico, aos seus olhos - e era do "espírito de comércio" que esperava a preparação de uma cidadania universal. A unificação do mundo se realizou, de certo modo, no revés dos Estados, graças ao comércio como pressentia Kant —, entretanto sem cidadania.

Insisto neste ponto, sob o risco de me repetir: diferentemente do Estado, os poderes que hoje em dia o limitam são, propriamente falando, impessoais. Trata-se das necessidades, das coações em relação às quais se tem prazer em sublinhar o caráter inelutável. Ou ainda: são os fluxos ${ }^{8}$, os processos sem sujeitos que podem gerar interdependências, mas não laços de fidelidade comunitárias. Os termos "globalização" ou "mundialização", na boca dos dirigentes políticos, sob a pluma dos jornalistas — ou para o cidadão comum, cujas representações se forjam pela leitura dos

8 Cf., por exemplo, Alain Arnaud: "A nova economia mundializada recoloca [...] em questão os símbolos do poder público: a soberania nacional e territorial, o controle e 0 monopólio da violência legítima e os meios de direcionar a organização econômica e social. Os fluxos transnacionais desprezam atualmente as fronteiras e recompõem os espaços segundo suas próprias modalidades" (ARNAUD, 1996, p. 89). jornais ou escuta dos discursos e declarações de seus dirigentes - não designam um deslocamento das instâncias de decisão comprometendo os destinos coletivos. Antes significam: ninguém governa, as instâncias de decisão são múltiplas, dispersas, com freqüência invisíveis ${ }^{9}$, sua imbricação constitui uma rede cujo comando ninguém detém ${ }^{10}$. O que torna o futuro da política problemático reside precisamente aí: a prevalência crescente de uma socialidade de redes em detrimento de socialidades identitárias ou, mais exatamente, em detrimento de um certo tipo de socialidade identitária, aquela que suporta o Estado. Por mais abstrata que seja a cidadania em comparação às formas tradicionais de fidelidades coletivas, ela permanece um vetor de identificação na medida em que o Estado soberano dispõe dos atributos da pessoa. As redes de interdependência criadas pelo fato da mundialização enfraquecem o poder efetivo de regulação do Estado e, com este poder, o fundamento da cidadania, sendo absoluta e constitutivamente incapazes de produzir uma solução alternativa. Mas nos guardemos, uma vez mais, de diagnósticos precipitados. O Estado se mantém ainda hoje um elemento central das identificações coletivas (ao menos isto é verdadeiro para o conjunto importante de países em que a forma Estado veio à luz; o juízo deve ser mais prudente em relação aos países em que essa forma aparece como importada, artificialmente imposta pelos poderes coloniais ou elites locais educadas no Ocidente, e às populações em que perduram os sistemas mais antigos de identificação). A cidadania, portanto, ainda mantém uma certa consistência. Mas essa consistência está ameaçada nos Estados europeus e na América do

9 Um ponto em que notadamente Monique ChemillierGendreau insiste, segundo uma perspectiva essencialmente jurídica. Assim: "Na sociedade internacional contemporânea os protagonistas são inidentificáveis. Os sujeitos de direito reconhecidos possuem apenas uma parte fraca na decisão. 0 sistema de reconhecimento identitário, tal como funcionou durante séculos, deixa na sombra os atores reais do papel cada vez maior do conjunto das trocas sociais" (CHEMILLIER-GENDREAU, 1995, p. 305).

10 Assim, Leo Sommer: "Globalização significa fronteiras abertas, concorrência mais acirrada, luta por suplantação. Ela subtrai à ação do Estado nacional o último espaço de manobra. A autoridade administra, mas quase não dá forma. Regulamenta-se, não se governa; o poder se fixa em uma gesticulação impotente, que pouco transforma as realidades". D ie Z eit, 3 de janeiro de 1997. 
Norte; e lá onde a cidadania jamais existiu ou apenas se estendeu a uma franja estreita da população, nos Estados ditos da "periferia", seu desenvolvimento é extremamente improvável sob os auspícios da mundialização. O problema não é que a preeminência da identidade política (estatal) seja discutida ou deva se compor junto a outras - o que, à sua maneira, traduz o sucesso das correntes comunitaristas. Não há nada de novo no fato de as fidelidades de grupo de um indivíduo serem diversas, e sua hierarquização, incerta e estável: a soberania do Estado teve desde sempre de se confirmar mediante a unificação lingüística, mediante a disputa do controle do ensino escolar com as Igrejas etc. Mas aquilo contra o qual o Estado se choca, principalmente hoje em dia, não são identidades coletivas alternativas, antigas ou novas, porém formas de socialização que não podem ser pensadas mediante as categorias de solidariedade e comunidade, poderes em relação aos quais não faria nenhum sentido questionar o fundamento normativo ou a legitimidade. Não há cidadania "onuense", dizíamos acima. A fortiori não pode haver cidadania do mundo enquanto a unidade deste for assegurada essencialmente pelos mercados ${ }^{11}$.

\section{SOCIALIZAÇÃO COMUNITÁRIA SEM COMUNIDADE: FIM DA HISTÓRIA?}

Mercados ou redes. A diferença não é muito grande. Talvez seja útil resumir o processo que estamos vivendo, afirmando que assistimos à vitória definitiva da economia sobre a política, simplesmente porque economia e política jamais estiveram separadas uma da outra tanto quanto uma certa Economia Política gostaria de supor. Mas seja qual for a relação entre economia e política, o mercado é provavelmente o núcleo e certamente o paradigma de uma socialidade de redes. Recordemos os termos com os quais Max Weber caracterizava a "comunidade" de mercado, termos que os socialistas de sua época por certo não recusariam: "A comunidade de mercado é como tal a relação prática de vida mais impessoal em que os

11 Isto por uma razão que Carl Schmitt resumiu de maneira brutal, mas ao meu ver pertinente: "Em uma sociedade cuja razão de ser é de ordem econômica e cuja organização, quer dizer, o funcionamento previsível, situase nas categorias econômicas, não é concebível - embora se possa imaginar - exigir de um membro qualquer que sacrifique sua vida no interesse do bom funcionamento dessa sociedade" (SCHMITT, 1963, p. 91). homens podem interagir. [...] O livre mercado, isto é, o mercado não cingido por regras éticas, com sua utilização de constelações de interesses, monopólios e oferta, subestima qualquer ética entre irmãos. O mercado está em completa oposição a todas as outras relações comunitárias que desde sempre pressupõem a fraternidade pessoal e, na maioria das vezes, laços consangüíneos, sendo toda fraternidade radicalmente estranha" (WEBER, 1922, p. 383). Weber opunha aqui o mercado às formas antigas, talvez primitivas, de vínculo social, a propósito das quais unicamente se pode falar em "fraternidade" e "laços consangüíneos". Em todo caso, também a cidadania funciona segundo uma lógica diferente da socialidade de redes, e assim como as comunidades de outrora, com algumas décadas ou séculos de atraso ela pode ser destruída pela expansão sem limites do tipo particular de socialização que o mercado exemplifica, aquele de uma relação comunitária sem comunidade.

A relação comunitária do mercado nada tem de fenômeno recente. Um dos paradoxos da "mudança" que vivemos no presente é que ela nada mais é, afinal de contas, que a consumação há muito preparada de um processo tão antigo quanto o próprio Estado moderno. Alguém que escreva a história da formação das sociedades modernas deve evidentemente dar tanta atenção à expansão da economia mercantil, ao alargamento e integração progressivos dos mercados locais, à criação dos bancos e instituições monetárias etc., quanto às diferentes etapas da afirmação do poder monárquico contra os poderes feudais, à uniformização do direito em cada Estado nacional, à evolução das formas constitucionais e à extensão do direito ao voto. Não somente os dois processos caminham em sintonia, mas são a tal ponto indissociáveis que é vão pretender discernir se remete à iniciativa do Estado o fato de ter permitido o desenvolvimento da economia capitalista, ou então se essa economia desenhou com o Estado moderno uma forma de poder político à sua conveniência. Pelo fato de a virtualidade de uma socialização de redes estar inscrita nas formas elementares do mercado e as trocas mercantis não ficarem de modo nenhum restritas às fronteiras dos Estados, também se percebeu há muito tempo a possibilidade de uma unificação do mundo que se realizaria sob a forma de uma necessidade cega: ao menos desde a metade do século XIX, por todos os autores que recusaram de uma maneira ou de outra o tema 
da naturalização da sociedade. Entre outros, por Marx — é claro - , que tentou penetrar até a raiz desse processo analisando o fetichismo da mercadoria, e por Max Weber, cujo voluntarismo político era uma resposta desesperada à expansão, segundo ele inexorável, de uma racionalização que tinha todos os ares de um fatum. Mas pode-se ver nessa temática, que adquire uma ressonância dramática na virada do século XIX para o XX e a partir desse momento alimenta todas as variedades da Kulturkritik, o avatar (e ao mesmo tempo o avesso) de uma idéia mais antiga que tomou forma com os filósofos escoceses do século XVIII e recebeu de Fergusson o nome "civilização”. A comparação entre essas duas épocas indica toda a ambivalência inerente ao esquema de uma socialização cega, essencialmente sustentada pelas trocas mercantis. Os autores do século XVIII desvendavam aí a promessa de uma transformação progressiva dos costumes e condutas, cujos efeitos transcendiam amplamente a esfera da atividade econômica no sentido estrito do termo: o fundamento de um progresso moral dos indivíduos, que tornava supérfluas as formas autoritárias de poder e autorizava a perspectiva de um progresso das liberdades políticas, sem que houvesse a necessidade de uma revolução. Ao final do século XIX, os efeitos civilizadores da economia capitalista se acham amplamente ocultados pela ameaça desde então percebida nos processos de socialização anônimos, a propósito dos quais se teve o tempo de descobrir que, abandonados à sua dinâmica natural, produzem de uma só vez a opulência e a miséria, a cultura e a barbárie. O sucesso da metáfora do mecanismo é o sintoma dessa avaliação totalmente inversa da socialização cega, assim como a crise da idéia de progresso.

Essa inversão se deve em grande parte à perda de credibilidade das filosofias da História do final do século XVIII e início do XIX, que pensavam a possibilidade de uma universalização do mundo mediante categorias incompatíveis com o reino das socialidades anônimas. Seria preciso uma análise cerrada para mostrar como a idéia de um processo de civilização, originalmente emprestada dos filósofos escoceses, fundiu-se com a idéia germânica de Bildung [formação], cujas premissas históricas eram sensivelmente diferentes. Foi essa fusão que autorizou a transfiguração teleológica da socialidade cega e é significativo que a política tenha sido o princípio dessa teleo- logia ${ }^{12}$ : não que os Estados governassem o curso da História (o papel conferido por Kant à "insociável sociabilidade dos homens" ou o estatuto do Espírito do Mundo, tribunal supremo da História em Hegel, excluem essa interpretação), mas porque foi definitivamente nas transformações das constituições políticas que o processo "natural" de transformação dos costumes adquiriu a qualidade de uma identidade refletida. Em outros termos, se a política não constituía a História, era o que lhe dava sentido. Somente a possibilidade de uma reflexão das transformações dos costumes em uma identidade conscientemente assumida permitia pensar a universalização do mundo em termos teleológicos.

"Globalização" é o nome que utilizamos recentemente para designar essa socialização às cegas, visto ter conseguido de fato englobar o mundo. Mas nos enganaríamos ao entender esse "englobar" em um sentido exclusivamente espacial, embora a extensão espacial seja um aspecto de sua existência: não há mais territórios no planeta que não sejam incluídos no raio de influência e ação das potências econômicas, ou ainda, não há mais nichos, por assim dizer, onde as populações possam perpetuar modos de vida que datam de outra época ${ }^{13}$. Mas a hegemonia da socialidade de redes implica também uma forma original de existência, cuja característica mais notável, do ponto de vista das expectativas dos séculos passados, é a de não se desenvolver na dimensão da História. A continuidade do processo histórico, levando da civilização à mundialização, não deve pois ocultar a maneira muito diferente pela qual é pensada, em cada uma dessas noções, respectivamente, a unidade da humanidade. É certo que as transformações das lógicas de socialização, nas quais os filósofos escoceses do século XVIII viam as premissas de uma humanidade nova, "civilizada", levaram à formação das redes de interdependência

120 que é verdadeiro em relação à história universal dos filósofos, Kant, Fichte e, bem entendido, Hegel, mas também em relação à história dos historiadores, como Schlözer no final do século XVIII, mas também Ranke algumas décadas mais tarde, apesar de sua declarada hostilidade contra a filosofia da História.

13 Sabe-se que é um dos problemas do etnólogo hoje em dia o fato de as formas de vida que ele procura descrever, e cuja lógica tenta modelar, não se apresentarem mais, em lugar nenhum, sob uma forma pura. 
planetárias que são hoje designadas pelo nome "mundialização". Mas a civilização era um processo, o que, estritamente falando, a mundialização não é. A civilização demandava tempo, o necessário para as lentas transformações dos modos de vida, dos modos de sentir e pensar bem como das formas de atividade. A mundialização, ao contrário, já está realizada e consumada em cada momento presente. A estrita sincronização do conjunto dos acontecimentos do mundo, que uma ampla literatura descreveu em todas as suas condicionantes, sobretudo tecnológicas, e em seus efeitos, no tocante aos ritmos de trabalho e de vida, é traduzida por uma presença de certo modo imediata da rede mundial das coações em cada momento da vida do indivíduo ${ }^{14}$.

Um sintoma do deslocamento de acento de uma para outra é verificável na história do conceito de habitus. Pierre Bourdieu inscreveu esse conceito no centro da conceitualização sociológica para ultrapassar a oposição clássica entre coações objetivas e disposições subjetivas em que se perdia a Sociologia francesa dos anos 60. Todavia, o esforço para pensar o ajustamento íntimo das disposições e condutas dos indivíduos às exigências das estruturas institucionais não data de ontem: a Gesinnung [disposição] hegeliana e notadamente a Lebensführung [conduta] weberiana (Weber, de resto, igualmente utiliza tanto o termo Gesinnung quanto ethos) podem ser consideradas, nesse sentido, as precursoras do habitus. E seria preciso, se fosse nosso propósito uma $\mathrm{Be}$ griffsgeschichte [história do conceito] exata e completa, remontar minimamente aos moralistas escoceses para mostrar que a noção germânica de Gesinnung, quaisquer que sejam as conotações morais e políticas que Hegel — depois de Kant pôde lhe imputar, beneficiou-se no início do século XIX de boa parte das significações de civilization, precisamente no momento em que se efetuava a

14 Um fenômeno que Norbert Elias, a quem devemos análises notáveis dos mecanismos de uma socialidade de rede, foi um dos primeiros a sublinhar. Assim: "Seja um burocrata ou um empresário na realização de seus compromissos ou negócios, seja um operário na afinação exata de cada trabalho manual em relação a uma determinação ou duração temporal, lá como cá o tempo é uma expressão da realização de ações que se interdependem, uma expressão do alcance e da densidade das redes em que convergem, como a parte no todo, as ações individuais" (ELIAS, 1976, p. 337). recepção da Economia Política inglesa na Alemanha. Sob o termo "civilização" eram pensadas conjuntamente tanto as inovações manifestas no plano da organização econômica, quanto as relações que as atividades industrial e mercantil mantinham com os poderes políticos, além das transformações mais discretas das expectativas, disposições, maneiras de agir e viver que acompanhavam essas inovações e relações. E precisamente porque a civilização incluía essas modificações íntimas - uma psicogênese, para falar como Elias - , permitia articular o político e o econômico: a civilitas [civilidade] preparava a civitas [cidade], o indivíduo, liberado dos vínculos tradicionais de sujeição e formado para a liberdade por sua investidura nas novas formas de atividade econômica, estava apto a reivindicar uma participação no jogo das instituições. Se a Gesinnung alemã absorveu o essencial das determinações da Zivilisation, autorizando a conjunção entre as idéias de um processo de civilização e do progresso das Luzes, o uso que hoje em dia se faz da noção de habitus parece-me sensivelmente diferente. $\mathrm{O}$ acento é dado à introjeção de coações próprias a um campo de atividade determinado, sem que o mecanismo dessa introjeção seja analisado com mais precisão. Sem, sobretudo, que ela seja pensada como solidária a uma transformação global das disposições do indivíduo, implicando novas maneiras de compreender a articulação dos diferentes coletivos que intervêm na compreensão do que esse próprio indivíduo é. A adaptação a um sistema de coações não civiliza, pois não engaja ou mobiliza senão uma faceta do indivíduo: cada campo faz valer suas exigências particulares e o sucesso, quer dizer, a adaptação bem-sucedida a um dos sistemas não prevê uma capacidade maior de se modelar às exigências de um outro. Nada permite supor que um trabalhador, coagido a se dobrar à disciplina da empresa devido a ausência de recursos próprios ou, em um registro mais recente, a aceitar, por não poder agir de outra maneira, os riscos da flexibilidade, modifique, por isso mesmo, a totalidade de sua relação com o mundo.

Se as interpretações teleológicas da História se tornaram caducas, isto não se deve ao fato de que o mundo do final do século XX realizou as promessas de ontem, quer dizer, ao fato de que teríamos chegado ao melhor dos regimes políticos possíveis, suscetível apenas de modificações de detalhe, mas se deve ao tipo de socialidade que 


\section{O CONCEITO DE POLÍTICA POSTO À PROVA PELA MUNDIALIZAÇÃO}

realizou a unidade do mundo. Essa unidade é efetiva apesar da pluralidade e ausência de hierarquia das instâncias de decisão. Ou, melhor ainda: é graças a essa pluralidade que o mundo é mundo, é ela que empresta à unidade do mundo, portanto, suas características distintivas. Ora, será que nos equivocamos ao nos inquietarmos com isso, e não deveríamos, antes, ver nessa situação a possibilidade de uma política diferente, liberada da tutela do Estado, liberada por isso mesmo de uma concepção hierárquica do poder, cujo núcleo era precisamente o dogma da soberania do Estado, concepção que constituía um obstáculo à consumação da democracia? Sublinha-se com justiça a multiplicidade das iniciativas de cidadania e movimentos sociais que se desenvolvem à margem dos quadros institucionais clássicos para contestar a idéia convencional de um recuo dos indivíduos à esfera da vida privada, em que se manifestaria um crescente desinteresse pela coisa pública. $\mathrm{O}$ imobilismo ou a impotência da política tradicional não impedem que a sociedade se transforme, e essas transformações oferecem aos cidadãos novos campos de ação e objetos para as intervenções coletivas, mediante as quais se elabora e trabalha continuamente o vínculo social. Todavia, parece-me um pouco apressado valer-se dessas metamorfoses das práticas coletivas para inferir um deslocamento puro e simples do lugar da política, de tal modo que sua compreensão devesse ser inteiramente repensada. Concluindo de modo precipitado o dossiê da história do Estado moderno sem demorar-se em um inventário minucioso, corre-se o risco de dar ao conceito de política uma plasticidade tão grande que termine perdendo toda significação determinada. Max Weber distinguia poder [pouvoir] e dominação, o primeiro termo designando "toda ocasião de impor sua própria vontade no interior de uma relação social, eventualmente contra uma resistência, quaisquer que sejam as condições sobre as quais repouse essa ocasião", enquanto o segundo implica que se efetue tal imposição nas formas do comando e da obediência ${ }^{15}$. Mas caracterizar o Estado como uma forma de dominação e fazer da relação comando/obediência o critério da dominação fere por demais profundamente as convicções democráticas e liberais de nossa época para que possamos

15 "D eve-se denominar dominação a ocasião em que certas pessoas se acham obedientes perante um comando de conteúdo determinado" (WEBER, 1922, p. 28). usar sem precaução essas definições. Seria preciso uma digressão muito longa para mostrar que a consideração das motivações da obediência, deixadas à sombra aqui, permite reduzir a aparente incompatibilidade entre a inter-pretação weberiana da natureza do poder de Estado (de sua dominação) e, por exemplo, o conceito de poder defendido por Hannah Arendt (1996) ${ }^{16}$. O que pretendo simplesmente sublinhar é o fato de que o conceito de poder, no sentido em que Weber o entende, é "sociologicamente amorfo" dada a ausência de determinação concernente às condições de sua efetividade (o que Weber denomina "as ocasiões sobre as quais ele repousa") ${ }^{17}$. O risco é tanto que não deveríamos dizer o mesmo a respeito da política ao focalizarmos a atenção na diversidade das expressões da cidadania, esquecendo as condições de sua existência. O que permitiu a constituição da cidadania - repitamos - foi a organização hierarquizada dos espaços de socialização, cujo ponto supremo era a preeminência do Estado. Só podíamos sonhar com outra cidadania -

16 O que está em jogo na elaboração conceitual feita por Hannah Arendt nesse ensaio é completamente diferente daquilo que inspira as definições weberianas. Em uma primeira leitura, as posições dos dois autores parecem diametralmente opostas. Hannah Arendt estigmatiza a "redução fatal do político ao domínio da dominação" (p. 45), e observa que os cidadãos da polis ateniense, assim como os da res publica romana, possuíam um conceito de poder e lei "cuja essência não repousa sobre a relação de comando e obediência, e que não identifica poder e dominação, ou lei e comando" (p. 41). Diferentemente da violência - este é o ponto que Hannah Arendt pretende destacar - , o poder pressupõe o consentimento do grupo no qual reside e pela concordância do qual existe. "Quando dizemos em relação a alguém que 'detém o poder', isto significa em realidade que está autorizado por um número determinado de pessoas a agir em nome delas" (p. 45). Mas esse "número determinado de pessoas" é precisamente 0 que aparece na definição weberiana da dominação ("por certas pessoas"), quer dizer, aquelas pessoas cuja obediência presumida dá consistência à dominação. A concordância sobre a qual repousa a obediência nada mais é que a legitimidade da dominação. 0 ra, tal legitimidade se deixa reconhecer na obediência com a qual o poder pode contar "quando uma decisão deve ser tomada" (p. 50) e, em vista disso, parece-me arbitrário afirmar que "a correlação comando-obediência é totalmente impertinente" (ibid.).

17 “O conceito 'poder' é sociologicamente amorfo. Todas as qualidades imagináveis de um ser humano e todas as constelações imagináveis podem colocar alguém na situação de impor sua vontade em uma dada circunstância” (WEBER, 1922, p. 28). 
cosmopolita, universal - sob a condição de pressupor a subordinação dos Estados a uma instância política supranacional, seja qual fosse a sua forma, quer dizer, sob a condição de pressupor a subordinação dos Estados a um poder legítimo (o que igualmente implica que sua legitimidade possa ser contestada). Ora, somente a autoridade é legitimável, e por esta razão é também uma forma de poder em torno da qual se pode constituir uma identidade coletiva. Algo totalmente diferente se passa com as redes, que inegavelmente criam vínculo social na medida em que as coações que exercem sobre os indivíduos são introjetadas em expectativas e disposições que levam em conta a existência dos outros (o dinheiro só dispõe da função que é a sua porque seu uso pressupõe a relação à atividade potencial dos outros indivíduos; o mesmo vale para todas as formas de relações negociadas entre os centros de decisão nãohierarquizados), mas escapam contudo à exigência de legitimação: exigência que seria absurda se formulada a seu respeito, pois a coação que impõem é da ordem da necessidade, não da obrigação.

Esquecemos facilmente as condições da cidadania porque esta de certo modo se tornou uma segunda natureza para nós, e o interesse coletivo se tornou uma noção manifesta, mesmo que seu conteúdo concreto seja sempre incerto e sua definição indefinidamente renegociada. Mas essas condições aparecem claramente quando consideramos os efeitos da hegemonia de uma socialidade de redes em populações nas quais ela se traduz em miséria e ausência de futuro, sem que essas populações tenham a possibilidade de elaborar suas dificuldades de existência e sua revolta contra uma cena política ausente: entre os jovens de bairros considerados problemáticos, no centro ou subúrbios das grandes metrópoles do núcleo antigo da Europa e na América do Norte, e em partes consideráveis, com freqüência majoritárias, dos povos da África ou América Latina. Esses sabem que as possibilidades que dispõem de "inventar sua própria biografia" são excessivamente restritas, talvez inexistentes, e só podem reivindicar direitos, sob formas pacíficas ou violentas, na medida em que possuem um interlocutor. Não apenas uma equipe dirigente, mas o próprio Estado aparece como impotente porque submetido às coações que o relegam a ponto de interditar toda a autonomia de sua ação; a miséria só pode engendrar a apatia, a fuga na droga ou a criminalidade, ou ainda a busca de identidades coletivas que substituam uma identidade cidadã impossível, o que consiste em uma das fontes dos fundamentalismos políticoreligiosos ou dos ressurgimentos do nacionalismo étnico. Não é o purismo teórico que nos faz hesitar em abandonar sem prudência o conceito "estatal" da política. A indeterminação de um conceito de política dissociado de sua referência tradicional ao Estado não seria um mal tão grande se não implicasse uma provável cegueira para a face obscura da socialidade de redes. Precisamente porque a mundialização já está consumada, ela inclui a certeza de um progresso indefinido (certeza dos progressos técnicos, da produtividade, do crescimento etc.) sem a promessa do futuro, ou ainda - para dizê-lo em termos hegelianos —, porque ela é um mau infinito, aquele da repetição do mesmo, não se pode considerar que os fenômenos que constituem essa face obscura sejam um fenômeno transitório, nem apostar que ela será a desfiliação (para retomar ainda um termo de Robert Castel) de grupos de indivíduos ou de populações inteiras, como a pauperização do século precedente, quer dizer, que poderemos tomá-la em algumas décadas por outro mal-estar de juventude, um mal-estar adolescente da história das sociedades modernas. Não foi o crescimento que reduziu espontaneamente a pauperização, mas as lutas sociais e políticas que arrancaram ao Estado as legislações que instituíram o direito trabalhista, as lincenças remuneradas, os sistemas de seguro e aposentadoria. Tais lutas, quaisquer que tenham sido as suas formas, desenvolviam-se no espaço da cidadania na medida em que pressupunham que o Estado estava apto a responder às suas reivindicações. Supondo que os Estados realmente não sejam outra coisa que um poder entre outros e o destino dos povos uma função do resultado imprevisível de um entrecruzamento de decisões cuja responsabilidade, bem entendido, nenhum sujeito institucional singular pode assumir, é vão esperar que os lados negativos da mundialização sejam algum dia corrigidos. E o mais grave, sem dúvida, para o futuro da política, é que as populações afetadas venham a se convencer da inexistência da autoridade soberana.

A dimensão hierárquica necessariamente implicada na compreensão estatal da política, dimensão na qual eu insistia ao evocar a questão das identidades, é extremamente suspeita hoje em dia. Supõe-se, no melhor dos casos, que é no fundo contraditória com a própria idéia de democracia; 
no pior, que comanda diretamente os projetos de uma constituição exclusivamente política da sociedade, projetos que vão desde os sonhos aparentemente inocentes dos utópicos do século XIX até os totalitarismos do século XX. Tentei mostrar que talvez a coisa não seja assim tão simples e que a preeminência reivindicada pelo Estado, que define o indivíduo como súdito, foi também o que permitiu a instituição e a conquista da cidadania. O Estado certamente não consentiu de maneira resoluta essa metamorfose do súdito em cidadão, que não foi nem está definitivamente concluída. A própria definição de cidadania, quer dizer, notadamente sua extensão e a natureza dos direitos que lhe são associados, é objeto de uma redefinição contínua, e o que chamamos política inclui todas as lutas que giram em torno dessa definição. Mas sem Estado, quer dizer, sem a convicção de que existe um poder capaz de reconhecer, conceder e garantir os direitos, não teria simplesmente existido o espaço onde se travam essas lutas. Os processos de democratização jamais colocaram seriamente em questão o poder do Estado, apenas as formas de seu exercício: é o que a globalização nos permite compreender na medida em que realmente ameaça, em contrapartida, esse poder, e com isto as bases da cidadania. Pois vale em geral para a socialidade de redes aquilo que vale para a burocracia (uma de suas manifestações), a respeito da qual Hannah Arendt observava que, quando se procura os responsáveis ou se exige reformas, não se acha ninguém: "não se pode contar, influenciar ou persuadir ninguém, sobre ninguém se pode exercer a pressão de um poder" (WEBER, 1922, p. 80).

Recebido para publicação em janeiro de 1999.

Catherine Colliot-Thélène (catherine.colliot-thélène@univ-rennes1.fr) é Profesora da Universidade de Rennes e Diretora da equipe de pesquisa "Filosofia Política Contemporânea" da Ecole Normale Supérieure de Fontenay/Saint-Cloud/CNRS. Publicou no Brasil Max Weber e a História (São Paulo, Brasiliense).

\section{REFERÊNCIAS BIBLIOGRÁFICAS}

ARENDT, H. 1996. Macht und Gewalt. München: Piper.

ARNAUD, A. 1996. Mondialisation et conflits. Agone, Paris, n. 16.

CASTEL, R. 1995. Les métamorphoses de la question sociale. Paris : Fayard.

CHEMILLIER-GENDREAU, M. 1995. Humanité e souverainetés. Paris : La Découverte.

ELIAS, N. 1976. Über den Prozeß der Zivilisation. Frankfurt/N. : Suhrkamp, Tome 2.

JESSOP, B. 1997. Die Zukunft des Nationalstaats: Erosion oder Reorganisation? Grundsätzliche Überlegungen zu Westeuropa. In: Jenseits der
Nationalökonomie? Weltwirtschaft und Nationalstaat zwischen Globalisierung und Regionalisierung. Berlin-Hamburg : Argument Verlag.

SCHMITT, C. 1963. La notion du politique. Paris : Calmann-Lévy.

von WEIZSÄCKER, R. 1992. Gespräch mit Gunther Hofman und Werner A. Perger. Frankfurt/M. : Eichborn.

WEBER, M. 1921. Politik als Beruf. In: Gesammelte Politische Schriften. München: Duncker \& Humblodt.

WEBER, M. 1922. Wirtschaft und Gesellschaft. Grundriss der Verstehenden Soziologie. Tubingen : J. C. B. Mohr (Paul Siebeck). 
ABSTRACTS RsocP vol. 121999

\section{THE CONCEPT OF POLITICS UNDER THE SCRUTINY OF MONDIALIZATION}

Catherine Colliot-Thélène (Ecole Normale Supérieure de Fontenay/Saint-Cloud)

This article characterizes the modern concept of politics in the light of the phenomena that have been designated by the term "globalization". It will be analized how the modern State has consolidated its capacity for domination as it has been able to formulate in structural and symbolic terms a colective identity, expressed through the idea of cityzenship. It is argued that the diversification of decision arenas and the transfer of economic, juridical and military competences to supranational, regional or transnational instances, question State sovereignty and at the same time begin to redefine a new the political sphere, given that power relations, in this new context, cease to be paralleled by processes of colective identification, that have, until now, been assured by the decision capacity of the State.

KEY WORDS: politics; State; sovereignty; collective identification; mondialization; globalization. 
LE CONCEPT DE POLITIQUE À L’ÉPREUVE DE LA MONDIALISATION

Catherine Colliot-Thélène (Université de Rennes/Ecole Normale Supérieure de Fontenay-SaintCloud/CNRS)

Cet article vise à caracterizar le concept moderne de politique en face des phénomènes designés para le terme “mondialisation”. On discute la consolidation de l'Etat en ce Qui concerne as capacité de domination dans la mesure où il se révèle apte à structurer symboliquement une identité collective particulière, traduite par l'idée de citoyenneté. On soutient que la diversification des champs de décision et le transfert des compétences économiques, juridiques et militaires aux instances supranationales, régionales ou bien transnationales, met en question la souveraineté d'Etat et commence à redéfir en même temps le champ de la politique de façon inouïe, puisque les relations de pouvoir dans ce nouveau contexte ne sont plus accompagnées des processus d'identification collective, jusqu’à présent assurés par la capacité de décision de l'Etat.

MOTS-CLES: politique; état; souveraineté; identification collective; mondialisation; globalisation. 